\title{
Paired-like homeodomain transcription factor 2 strengthens chemoresistance in colorectal cancer by activating the Wnt/ $\beta$-catenin axis
}

\author{
Yuxian $\mathrm{SHU}^{1}$, Chuan $\mathrm{HE}^{2}$, Yan XIONG ${ }^{2}$, Jun $\mathrm{LAN}^{3}$, Rongfeng SONG ${ }^{2, *}$ \\ ${ }^{1}$ Department of Breast Radiotherapy, Jiangxi Cancer Hospital, Nanchang, Jiangxi, China; ${ }^{2}$ Department of Gastroenterology, Jiangxi Cancer \\ Hospital, Nanchang, Jiangxi, China; ${ }^{3}$ Department of General Surgery, Gao'an people's Hospital, Nanchang, Jiangxi, China \\ *Correspondence: xn81235ch213@163.com
}

Received October 31, 2020 / Accepted January 14, 2021

\begin{abstract}
The purpose of this study was to determine the mechanism of paired-like homeodomain transcription factor 2 (PITX2) in the chemoresistance of colorectal cancer (CRC) via the upregulation of the Wnt/ $\beta$-catenin axis. CRC cells were persistently exposed to increasing 5-fluorouracil (5-FU) concentrations to establish 5-FU-resistant cells. Functional assays were conducted to examine cell viability, proliferation, and cell cycle. After the transfection of small interfering (si)-negative control and si-PITX2 in 5-FU-resistant cells, the effects of PITX2 depletion in these cells were assessed. Notably, expression of PITX2, Wnt-3a, and $\beta$-catenin, and the relation between PITX2 and Wnt-3a were verified. Additionally, an inhibitor or an activator of the Wnt/ $\beta$-catenin axis was added into cells to detect the variance of the 5-FU-resistant cells. Eventually, xenograft transplantation was applied to confirm the effect of PITX2 knockdown on CRC chemoresistance to 5-FU. 5-FU-resistant CRC cells were successfully established, in which CRC cell viability, proliferation, and cell cycle were all enhanced, while PITX2 knockout led to reversed results, indicating that resistance to 5-FU in CRC was restricted. Furthermore, our findings revealed that PITX2 upregulated the Wnt $/ \beta$-catenin axis. The inactivation of the Wnt $/ \beta$-catenin axis resulted in the reduction of resistance to 5-FU in CRC cells; while activation of the Wnt/ $\beta$-catenin axis reversed the reduced resistance to 5-FU in CRC cells caused by PITX2 knockout. Additionally, xenograft transplantation further confirmed that PITX2 knockdown reduced the resistance of HCT-116 cells to 5-FU. This study clarified that PITX2 enhanced resistance to 5 -FU in CRC upregulating the $\mathrm{Wnt} / \beta$-catenin axis.
\end{abstract}

Key words: colorectal cancer, 5-fluorouracil, paired-like homeodomain transcription factor 2, Wnt/ $\beta$-catenin signaling pathway, proliferation

Colorectal cancer (CRC) represents the second largest malignant disease in females and the third males globally, which is responsible for the skyrocket incidence and mortality rate in recent years $[1,2]$. It is a human malignancy with complex factors and different stages which is relevant to the impairment of gut microbiota [3]. Age, smoking, obesity, unhealthy diet, and insufficient physical exercise are identified as the induction of CRC [4]. A series of tumor screening interventions have helped to diagnose subjects with CRC and restrict the numbers of morbidity and deaths over the years [5]. Moreover, the overall survival rate of CRC is largely improved as various therapies were developed, for instance, immunotherapy, radiotherapy, palliative chemotherapy, surgical excision, targeted therapy, and extensive surgery [4]. On the other hand, although chemotherapy such as the treatment of 5-fluorouracil (5-FU) may greatly relieve CRC, it could also impose chemoresistance and even generate frustrating clinical outcomes in return [6]. Wherefore, finding proper molecular markers is significant in administrating appropriate chemotherapies and personalized treatment that may generate a benign prognosis for CRC [1].

Previous progress has discovered that paired-like homeodomain transcription factor 2 (PITX2) could act as an effective biomarker in human cancer diagnosis and prognosis [7]. Pellatt et al. declared that PITX2 is dysregulated in CRC progression [8], triggering us to probe the specific mechanism of PITX2 in CRC. What's more, since PITX2 activities are increasingly observed at the initial phase of CRC oncogenesis, it is acknowledged as a promising molecular marker that is associated with peril classification and unfavorable prognosis [9]. Lee and his colleague found that PITX2 imposes multidrug resistance on renal cancer by impeding the absorption of sensitizing medicine and strengthening the drain of cytoprotective medicine [10]. Although the role of PITX2 in 
cancers gets plenty of attention, the interconnection between PITX2 and related pathway is less discussed. For instance, the Wnt/ $\beta$-catenin axis, a hot topic in cancers, can regulate stem cells to intensify tumor pathologies [11]. It is reported that the Wnt/ $\beta$-catenin axis downregulation is coupled by the limited CRC cell expansion, cell colony formation, and cell number in differentiated carcinoma organoids, indicating the detrimental function the $\mathrm{Wnt} / \beta$-catenin pathway play in CRC [12]. Importantly, the simultaneous exhaustion of PITX2 and the Wnt/ $\beta$-catenin pathway contributes to the suppression of cell dissemination, biological activities, and epithelial-mesenchymal transition in various cancers including breast cancer, lung adenocarcinoma, and thyroid cancer [13-15]. Therefore, there is a high chance that PITX2 could collaborate with the Wnt/ $\beta$-catenin axis to exacerbate CRC. And we hope our experiment could offer some novel insights for CRC chemoresistance reduction.

\section{Materials and methods}

Cell culture and treatment. CRC cells SW480 and HCT-116 (Cell Bank of Chinese Academy of Sciences, Shanghai, China) were cultured in Dulbecco's modified Eagle's medium containing $10 \%$ fetal bovine serum in a $37^{\circ} \mathrm{C}$ incubator with $5 \% \mathrm{CO}_{2}$. SW480 and HCT-116 cells were persistently exposed to increasing concentrations of 5-FU (Sigma-Aldrich, Merck KGaA, Darmstadt, Germany) for 2 $\mathrm{h}$ with the purpose of establishing 5-FU-resistant cells. Then, the half-maximal inhibitory concentration of 5 -FU $\left(\mathrm{IC}_{50}\right)$ was calculated, and the successfully established resistant cells were recorded as SW480/5-FU and HCT-116/5-FU cells, respectively. Subsequently, small interference (si)-negative control (NC) or si-PITX2 (both from Guangzhou RiboBio Co., Ltd, Guangzhou, Guangdong, China) was transfected into these 5-FU-resistant cells, which were then treated with KYA1797K and lithium chloride ( $\mathrm{LiCl}$ ) (activator of the Wnt/ $\beta$-catenin axis; [16]) (both from Sigma-Aldrich). The transfection was carried out via Lipofectamine ${ }^{\mathrm{TM}} 2000$ (Invitrogen Inc., Carlsbad, CA, USA), and after $48 \mathrm{~h}$ of transfection, further steps were conducted.

3-(4, 5-dimethylthiazol-2-yl)-2, 5-diphenyltetrazolium bromide (MTT) assay. Cells $\left(1 \times 10^{5} / \mathrm{ml}\right)$ at the logarithmic phase were seeded in 96-well plates. At $0 \mathrm{~h}, 24 \mathrm{~h}, 48 \mathrm{~h}, 72 \mathrm{~h}$, and $96 \mathrm{~h}$ of cultivation, respectively, $100 \mu \mathrm{l}$ phosphate buffer saline (PBS)-dissolved MTT ( $5 \mathrm{mg} / \mathrm{ml}$ ) was added into cells, which were incubated in a $37^{\circ} \mathrm{C}$ incubator with $5 \% \mathrm{CO}_{2}$. The supernatant was discarded after $4 \mathrm{~h}$. Cells were incubated with $100 \mu$ dimethyl sulphoxide (DMSO) and were then gently percussed for $10 \mathrm{~min}$. Consequently, the optical density at $450 \mathrm{~nm}$ was determined using a Thermo Scientifisher microplate reader (Thermo Fisher Scientific Inc., Waltham, MA, USA).

Colony formation assay. Cells $\left(2 \times 10^{3} /\right.$ well $)$ of each group were seeded into 6-well plates. Two or three weeks later, cells were rinsed with PBS, fixed by paraformaldehyde, and subjected to a 4 min staining with $0.1 \%$ crystal violet (Beijing Solarbio Science \& Technology Co., Ltd., Beijing, China). Cell colonies were observed with the naked eyes.

Flow cytometry. Cells $\left(2 \times 10^{6}\right)$ were inoculated into 100 $\mathrm{mm}$ cell culture dishes for the overnight fixation, which was followed by a wash in PBS and a 30 min staining with propidium iodide (PI) (Sigma) and RNase A (MBI Fermentas Inc., Hanover, MD, USA) at the ratio of $40 \times \mathrm{PI}$ $(2 \mathrm{mg} / \mathrm{ml}): 100 \times$ RNase $(10 \mathrm{mg} / \mathrm{ml}): 1 \times \mathrm{PBS}=25: 10: 1,000$. Cell cycle profiles were analyzed by the BD FACSCalibur flow cytometer system (BD, Biosciences, Franklin Lakes, NJ, USA). CellQuest Pro software was employed to analyze the collected data (BD BioSciences).

Dual-luciferase reporter gene assay. The binding site between PITX2 and Wnt-3a promoter was predicted through the JASPAR database (http://jaspar.genereg.net/). The fragment sequence in the Wnt-3a binding site was synthesized and inserted into the pGL3-basic vector, and then co-transfected into SW480 and HCT-116 cells with si-PITX2 and si-NC by Lipofectamine ${ }^{\mathrm{rm}} 2000$. After $48 \mathrm{~h}$ of transfection, luciferase activity was measured by a fluorescence detector (Promega, Madison, Wisconsin, USA). This experiment was conducted 3 times.

RNA immunoprecipitation (RIP) assay. SW480 and HCT-116 cells were resuspended in nuclear isolation buffer and placed on ice for $30 \mathrm{~min}$ at least with continuous mixing. The pellet nuclei were resuspended in wash buffer and $1 \times$ protease inhibitor cocktail (both from Solarbio), and they trimmed the chromatin using high-power sonication. Afterward, $90 \%$ nuclei were cultivated with $1 \mu \mathrm{g}$ of PITX 2 antibody overnight, and $40 \mu \mathrm{l}$ Protein $\mathrm{A} / \mathrm{G}$ beads (Thermo Fisher Scientific) via mild circulation for $2 \mathrm{~h}$ at $4^{\circ} \mathrm{C}$. The remaining $10 \%$ were collected as input. The pellet beads were centrifuged at 3,000 rpm for $3 \mathrm{~min}$ and rinsed 3 times. Finally, the Wnt-3a expression was detected by western blot analysis.

Quantitative real-time polymerase chain reaction (qRT-PCR). TRIzol kits (Beyotime Biotechnology Co., Ltd, Shanghai, China) were employed in the total RNA extraction in each group to testify the purity and concentration of the total RNA. Following the instructions of the Rever Tra Ace qPCR RT Master Mix kits (Toyobo Co., Ltd., Tokyo, Japan), RNA was reversely transcribed to cDNA. Fluorescence qPCR was conducted according to the instructions of the SYBR Premix Ex Tap ${ }^{\mathrm{TM}}$ II kits (Takara Bio Inc., Kyoto, Japan). PCR conditions were: 40 cycles of pre-denaturation at $95^{\circ} \mathrm{C}$ for 10 min, denaturation at $95^{\circ} \mathrm{C}$ for $15 \mathrm{~s}$, and annealing at $60^{\circ} \mathrm{C}$ for $1 \mathrm{~min}$. And the $2^{-\Delta \Delta \mathrm{Ct}}$ method was applied for relative expression calculation of genes with glyceraldehyde-3-phosphate dehydrogenase (GAPDH) as the internal reference. The primer sequence is listed in Table 1.

Western blot analysis. The total protein of cells in each group was extracted, and its concentration was determined, with $12 \%$ separation gel and 5\% spacer gel pre-prepared. Next, the proteins were transferred onto the polyvinylidene fluoride membranes after sodium dodecyl sulfate polyacryl- 
amide gel electrophoresis. Afterward, the membranes were sealed by $5 \%$ skim powder milk for $1 \mathrm{~h}$ and then cultivated with the primary antibodies: PITX2 (\#P0998, 1:1,000; SigmaAldrich), Wnt-3a (ab28472, 1:1,000; Abcam Inc., Cambridge, MA, USA), and $\beta$-catenin (\#8480, 1:1,000; Cell Signaling Technology, Beverly, MA, USA) at $4{ }^{\circ} \mathrm{C}$ overnight. Afterward, the membranes were incubated with horseradish peroxidase (HRP)-labeled anti-rabbit immunoglobulin G (IgG) (ab6276, 1:2,000; Abcam) for $1 \mathrm{~h}$ at room temperature. After the exposure, the images of these membranes were obtained via a gel imaging system. $\beta$-actin (\#8457, 1:1,000; Cell Signaling Technology) worked as the internal reference and the ratio of the gray value of the target band to the $\beta$-actin band is acknowledged as the relative expression of the protein.

Xenograft tumors in nude mice. Twenty BALB/c male nude mice (4-5-week-old, 15-18 g) (Hunan SJA Laboratory Animal Co., Ltd., Changsha, Hunan, China) were numbered according to their body weights and then split into the sh-NC + PBS group, the sh-PITX2+PBS group, the sh-NC+5-FU group, and the sh-PITX2+5-FU group $(\mathrm{n}=5)$. Subsequently, $200 \mu \mathrm{l}$ HCT-116 cell suspension $\left(1 \times 10^{6}\right.$ cells $\left./ \mathrm{ml}\right)$ transfected with sh-NC or sh-PITX2 respectively, was subcutaneously injected into nude mice through the left side [17]. Moreover, mice in the sh-NC+5-FU group and the sh-PITX2+5-FU group were treated with intraperitoneal administration of 5 -FU $(50 \mathrm{mg} / \mathrm{kg}$ ) once a week for 3 weeks. Tumor volume was assessed using a vernier caliper every week, and it was measured as $\mathrm{V}=\left(\mathrm{L} \times \mathrm{W}^{2}\right) \times 0.5$, with $\mathrm{L}$ representing tumor length and $\mathrm{W}$ representing tumor width [18]. Mice were euthanatized at the $4^{\text {th }}$ week with their tumors separated and weighed to prepare the paraffin sections, which were used for following Ki67 immunohistochemical staining. The protocol was granted by the Institutional Animal Care and Use Committee of Jiangxi Cancer Hospital. Great efforts were made to reduce animal numbers used and their anguish.

Immunohistochemical staining. Tumor specimens were fixed with $4 \%$ paraformaldehyde solution and regularly sliced into paraffin-embedded sections, which were dewaxed to hydrate, soaked in PBS buffer solution twice $(2 \mathrm{~min} / \mathrm{each}$ time), and subjected to antigen retrieval using $\mathrm{pH} 6.0$ citrate and high-pressure steam. Endogenous peroxidase-induced specific background staining was exhausted by 10-15 min-incubation with $3 \% \mathrm{H}_{2} \mathrm{O}_{2}$. Afterward, sections were immersed in PBS buffer solution 3 times ( $2 \mathrm{~min} / \mathrm{each}$ time), incubated with primary antibody Ki67 (\#12202, 1:500; Cell Signaling Technology) at $37^{\circ} \mathrm{C}$ for $3 \mathrm{~h}$, and again rinsed by PBS buffer solution 5 times ( $2 \mathrm{~min} / \mathrm{each}$ time). Sections were then cultivated with HRP-labelled goat anti-rabbit IgG second antibody (\#8114, 1:200; Abcam) at $37^{\circ} \mathrm{C}$ for $10-15 \mathrm{~min}$ and soaked in PBS buffer solution 5 times $(2 \mathrm{~min} /$ each time). Subsequently, sections were developed by 2 , 4-diaminobutyric acid for 3-5 min, cleaned by running water for $3 \mathrm{~min}$, cleaned using distilled water for once, counterstained using hematoxylin, rinsed by flowing water, dried, dehydrated, transparentized, and sealed. In the NC group,
Table 1. Primer sequence of qRT-PCR.

\begin{tabular}{ll}
\hline Gene & Sequence (5'-3') \\
\hline PITX2 & F: 5'-ACTTTACCAGCCAGCAGCTC-3' \\
& R: 5'-GGGTACATGTCGTCGTAGGG-3' \\
GAPDH & F: 5'-GAGTCAACGGATTTGGTCGT-3' \\
& R: 5'-TTGATTTTGGAGGGATCTCG-3' \\
\hline
\end{tabular}

Notes: qRT-PCR-quantitative real-time polymerase chain reaction; PITX2paired-like homeodomain transcription factor 3; GAPDH-glyceraldehyde3-phosphate dehydrogenase; F-forward; R-reverse

Ki67 was replaced by PBS. Sections were blindly inspected by 2 independent pathologists. Ki67 staining was scored by the result of staining intensity multiplying the percentage of positive cells, with staining intensity classified into 4 grades (no staining, 0 ; weak staining, 1; moderate staining, 2; intensive staining, 3 ) and the percentage of positive cells also divided into 4 grades $(0 \%, 0 ; 1-25 \%, 1 ; 26-50 \%, 2 ; 51-75 \%$, 3; 76-100\%, 4) [19].

Statistical analysis. SPSS 21.0 (IBM Corp. Armonk, NY, USA) was employed to analyze data. Kolmogorov-Smirnov test indicated the data were normally distributed. The data were shown as mean \pm standard deviation. The $t$-test was used for analyzing comparisons between two groups, one-way analysis of variance (ANOVA) and two-way ANOVA for comparing different groups, and Tukey's multiple comparisons test for pairwise comparisons after ANOVA. The $\mathrm{p}$-value was attained using a two-tailed test and $\mathrm{p}<0.05$ or $\mathrm{p}<0.01$ referred to a significant difference.

\section{Results}

The successful establishment of 5-FU-resistant cells promotes CRC cell proliferation. 5-FU-resistant SW480 and HCT-116 cells were established to investigate the mechanism of chemoresistance in CRC as the two kinds of cells above were persistently exposed to increasing 5-FU concentrations to calculate the value of $\mathrm{IC}_{50}$. The results revealed that the viability of SW480 and HCT-116 cells were gradually decreased with the continuous increase of 5-FU concentration, and the $\mathrm{IC}_{50}$ values of SW480/5-FU and HCT-116/5-FU cells were significantly greater than those of the parental ones (SW480 and HCT-116 cells) (all p $<0.01$, Figure 1A), indicating that SW480/5-FU and HCT-116/5-FU cells were successfully established. In addition, SW480/5-FU and HCT-116/5-FU cells expressed elevated viability and proliferation, and increased cells in the $S$ phase compared with the parental cells (all $p<0.05$, Figures $1 \mathrm{~B}, 1 \mathrm{C}$ ). These findings showed that 5-FU treatment promoted CRC cell proliferation.

PITX2 exhaustion attenuates resistance to 5-FU in CRC. It was found that PITX2 expression was significantly higher in SW480/5-FU and HCT-116/5-FU cells than that in the parental cells (all $\mathrm{p}<0.001$, Figures 2A, 2B). When 


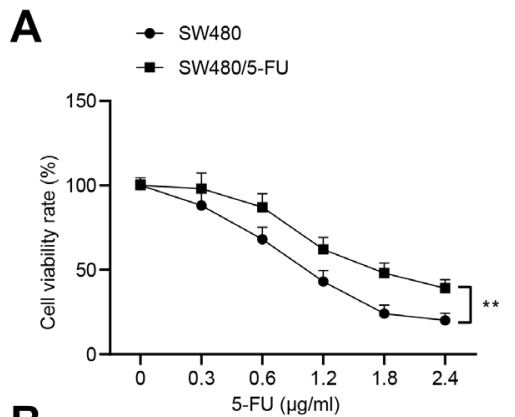

B

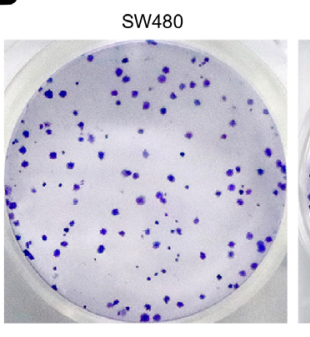

C

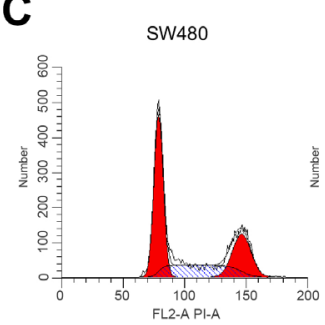

SW480/5-FU

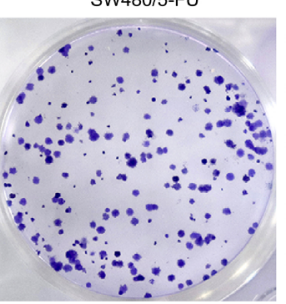

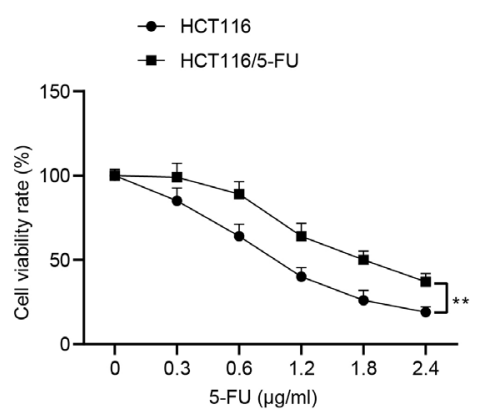
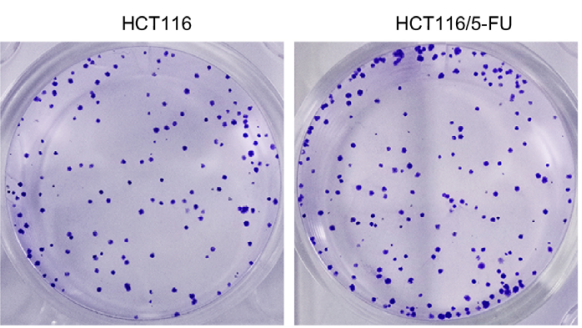
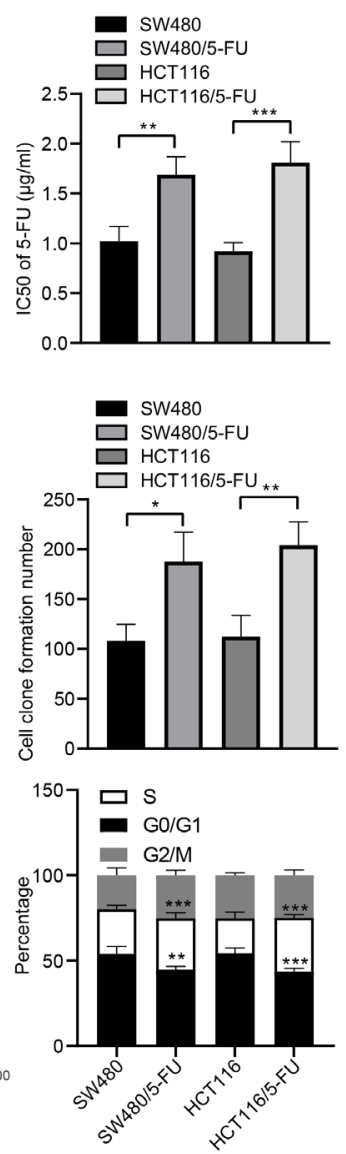

Figure 1. The successful establishment of 5-FU-resistant cells promotes CRC cell proliferation. A) cell viability assessed by MTT assay. B) Cell proliferation measured by the colony formation assay. C) Cell cycle verified by a flow cytometer. Replicates $=3$. The data are shown as mean \pm standard deviation. The t-test and two-way ANOVA were used to analyze data. Tukey's multiple comparisons test was applied for the post hoc test. ${ }^{\star}$ p $<0.05$, ${ }^{* *} \mathrm{p}<0.01,{ }^{* * *} \mathrm{p}<0.001$

PITX2 expression was downregulated in SW480/5-FU and HCT-116/5-FU cells (both $\mathrm{p}<0.001$, Figures 2C, 2D), SW480/5-FU and HCT-116/5-FU cell viability was reduced, proliferation was restricted, and cells in the $S$ phase were decreased (all $p<0.05$, Figures $2 \mathrm{E}-2 \mathrm{G}$ ), indicating that the PITX2 exhaustion attenuated resistance to 5-FU in CRC.

PITX2 transcriptionally activates Wnt-3a expression to upregulate the Wnt $/ \boldsymbol{\beta}$-catenin axis. It was predicted by the online software JASPAR (http://jaspar.genereg.net) that there was a binding site between PITX2 and Wnt-3a promoter (Figure 3A). RIP assay demonstrated that PITX2 directly bound to Wnt-3a promoter in SW480 and HCT-116 cells $(p<0.01$, Figure 3B). As shown in the dual-luciferase reporter gene assay, PITX2 knockdown in SW480 and HCT-116 cells inhibited Wnt-3a-wild type luciferase activity (both $\mathrm{p}<0.01$, Figure 3C). Additionally, when PITX2 expression was downregulated in SW480/5-FU and HCT-116/5-FU cells, levels of Wnt-3a and $\beta$-catenin, proteins involved in the $\mathrm{Wnt} / \beta$-catenin axis, were discouraged in SW480/5-FU and HCT-116/5-FU cells (both $\mathrm{p}<0.01$, Figure 3D). The results above supported that PITX2 transcriptionally activated Wnt-3a expression and thus activate the $\mathrm{Wnt} / \beta$-catenin axis.

Downregulation of the $W n t / \beta$-catenin axis limits the resistance to 5-FU in CRC. To figure out the effect of the Wnt $/ \beta$-catenin axis on 5 -FU resistance in CRC, this research treated SW480/5-FU and HCT-116/5-FU cells with KYA1797K, an inhibitor of the Wnt/ $\beta$-catenin axis. And it was found that with KYA1797K treatment, $\beta$-catenin expression was significantly restricted, cell viability was quenched, proliferation was attenuated, and cells in the $S$ phase were limited in SW480/5-FU and HCT-116/5-FU cells (all $p<0.01$, Figures $4 \mathrm{~A}-4 \mathrm{D})$. That's to say, the inactivation of the $\mathrm{Wnt} / \beta$ catenin axis limited the resistance to 5-FU in CRC.

Activation of the $W n t / \beta$-catenin axis reverses the reduced resistance to 5-FU in CRC caused by the PITX2 knockdown. To further test PITX2 mediated CRC cell resistance to 5 -FU through the $\mathrm{Wnt} / \beta$-catenin axis, we performed functional rescue experiments in SW480/5-FU and HCT-116/5-FU cells via the administration of si-PITX2 + DMSO, si-PITX2 + LiCl. The results discovered that PITX2 

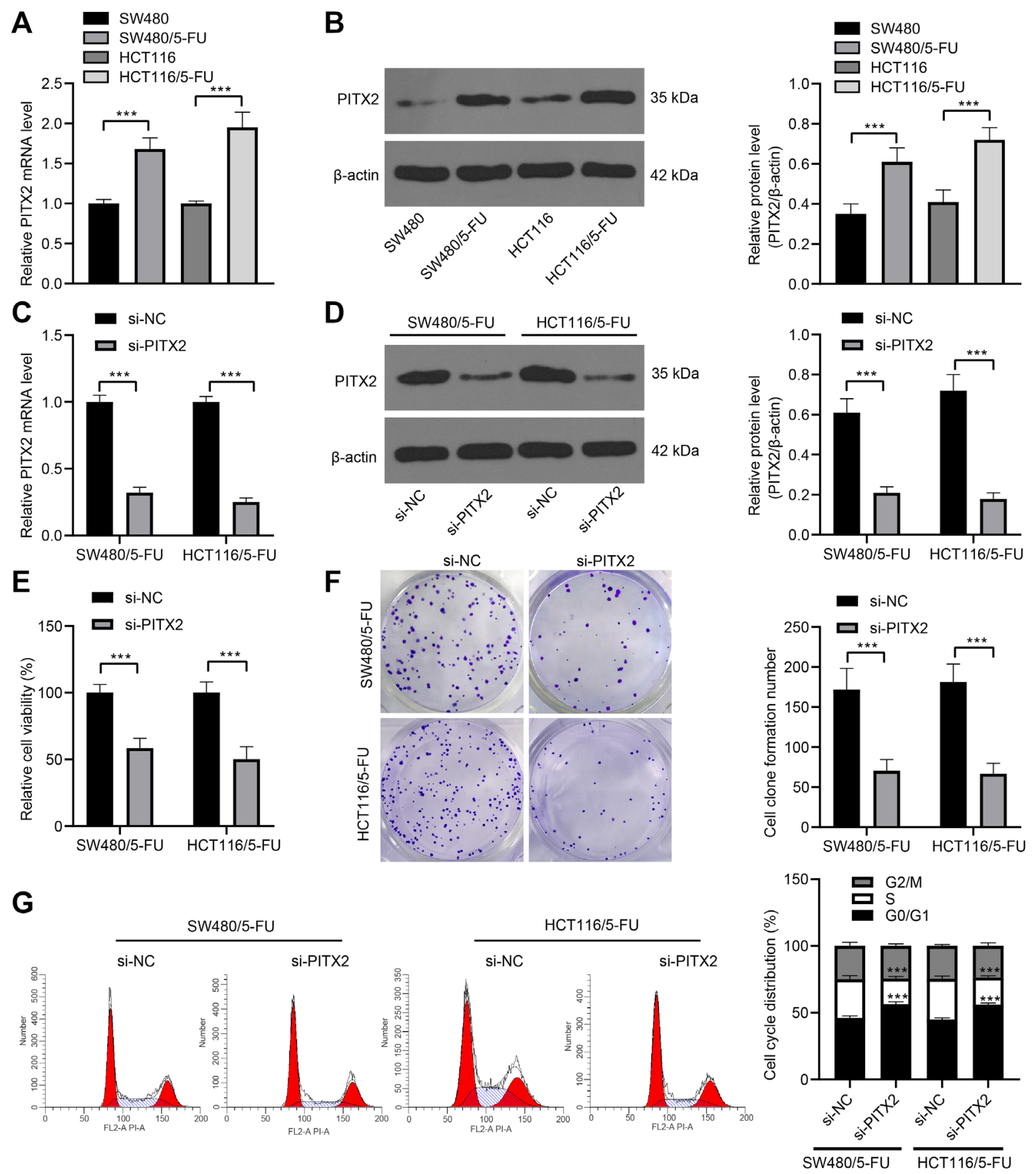

Figure 2. PITX2 exhaustion attenuates the resistance to 5-FU in CRC. A, B) PITX2 expression in SW480/5-FU cells, HCT-116/5-FU cells, and their parental cells detected by qRT-PCR (A) and (B). C, D) PITX2 expression in SW480/5-FU and HCT-116/5-FU cells after PITX2 knockdown verified via qRT-PCR (C) and western blot analysis (D). E) Cell viability detected by MTT. F) Cell proliferation measured using the colony formation assay. G) Cell cycle examined by a flow cytometer. Replicates $=3$. The data are shown as mean \pm standard deviation. The $t$-test and two-way ANOVA were used to analyze data. Tukey's multiple comparisons test was applied for the post hoc test. ${ }^{\star} \mathrm{p}<0.05,{ }^{\star *} \mathrm{p}<0.01,{ }^{* *} \mathrm{p}<0.001$

expression was unchanged, while $\beta$-catenin expression was increased after $\mathrm{LiCl}$ treatment (both $\mathrm{p}<0.01$, Figures $5 \mathrm{~A}-5 \mathrm{C}$ ). Moreover, after $\mathrm{LiCl}$ treatment, cell viability was encouraged, proliferation was potentiated, and cells in the $S$ phase were increased (all $\mathrm{p}<0.01$, Figures $5 \mathrm{D}-5 \mathrm{~F}$ ). Our data suggested that the activation of the $\mathrm{Wnt} / \beta$-catenin axis reversed the reduced 5-FU resistance in CRC cells resulted from PITX2 knockdown.

PITX2 knockdown in vivo attenuates HCT-116 cell resistance to 5-FU. To verify the effect of PITX2 on CRC cell 
A

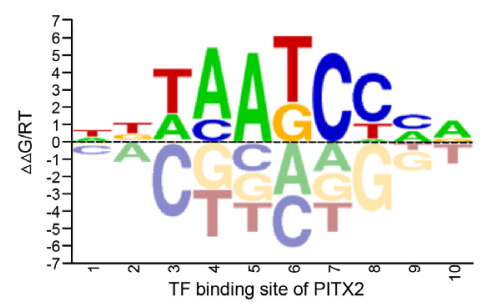

B

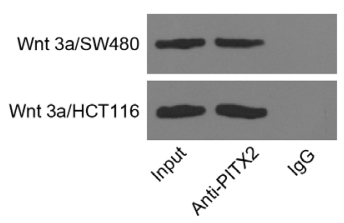

\begin{tabular}{l|c|c|c|c|c|c|c|} 
Sequence name & Start & Stop & Strand & Score & $P$ Value & $Q$ Value & Matched Sequence
\end{tabular}
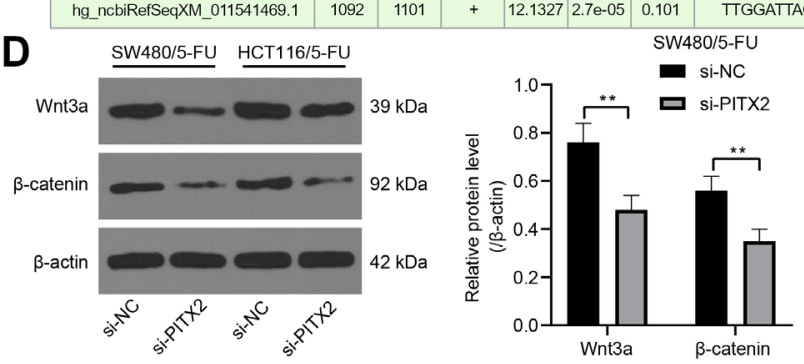
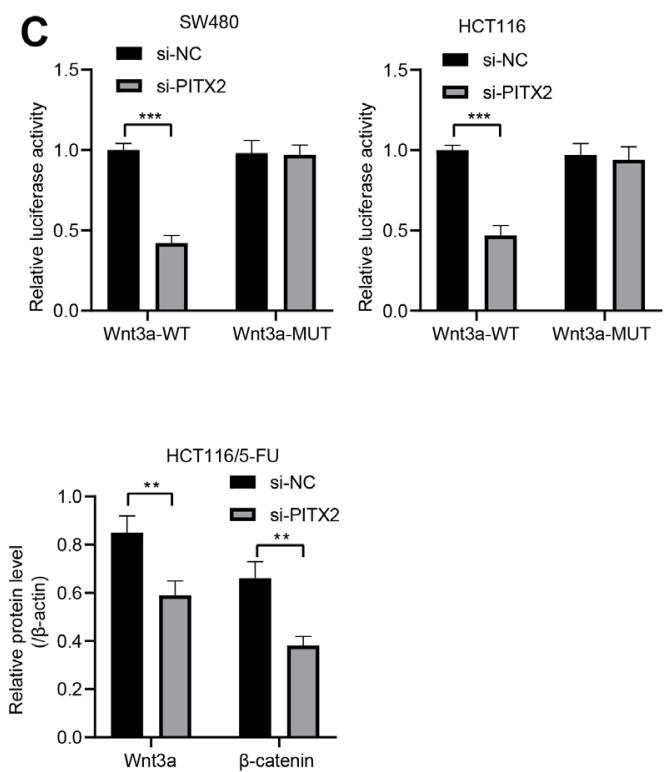

Figure 3. PITX2 transcriptionally activates the Wnt-3a expression to upregulate the Wnt/ $\beta$-catenin axis. A) The binding site between PITX2 and Wnt3a predicted through JASPAR. B, C) The interaction between PITX2 and Wnt-3a detected by RIP (B) and dual-luciferase reporter gene assay (C). D) Levels of Wnt-3a and $\beta$-catenin in SW480/5-FU and HCT-116/5-FU cells examined via western blot analysis. Replicates $=3$. The data are shown as mean \pm standard deviation. The t-test was used to analyze data. ${ }^{* *} \mathrm{p}<0.01,{ }^{* * *} \mathrm{p}<0.001$
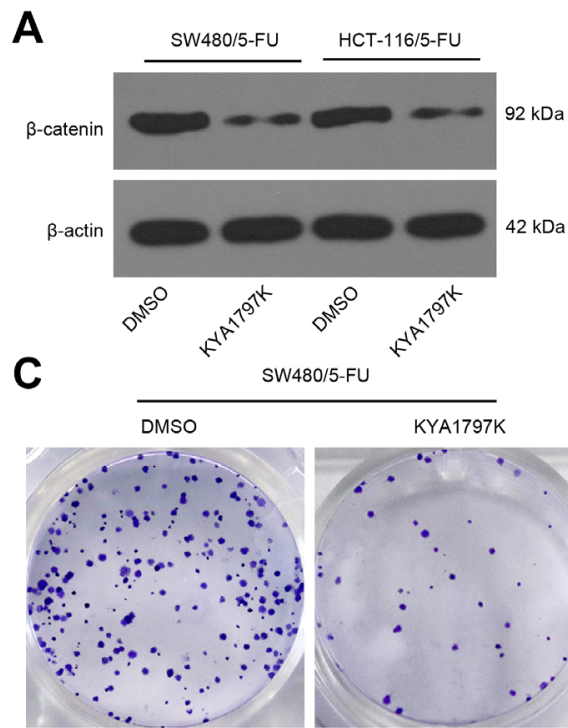

D

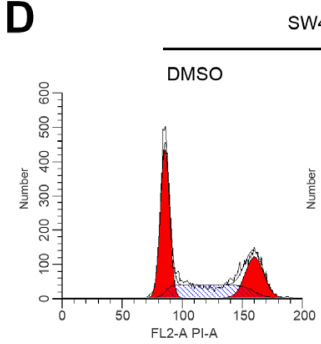

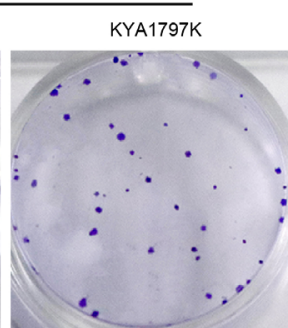

W480/5-FU

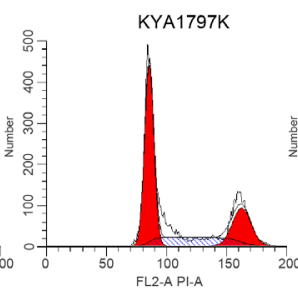

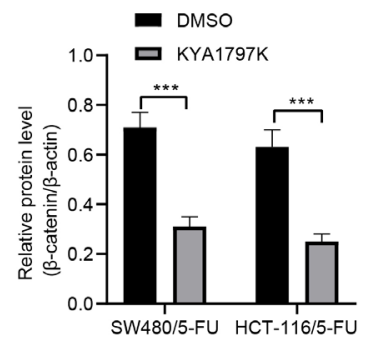

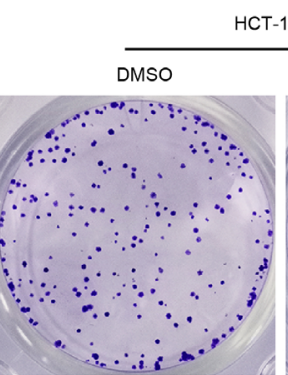

HCT-116/5-FU
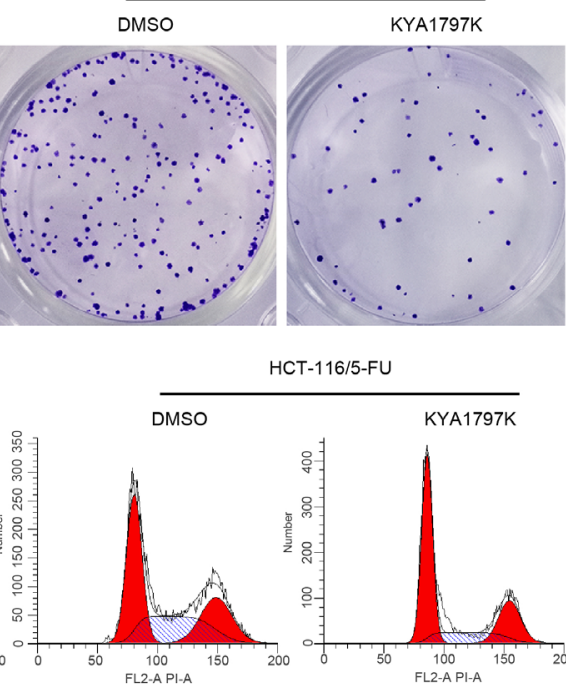

HCT-116/5-FU

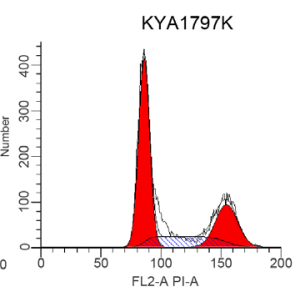

B
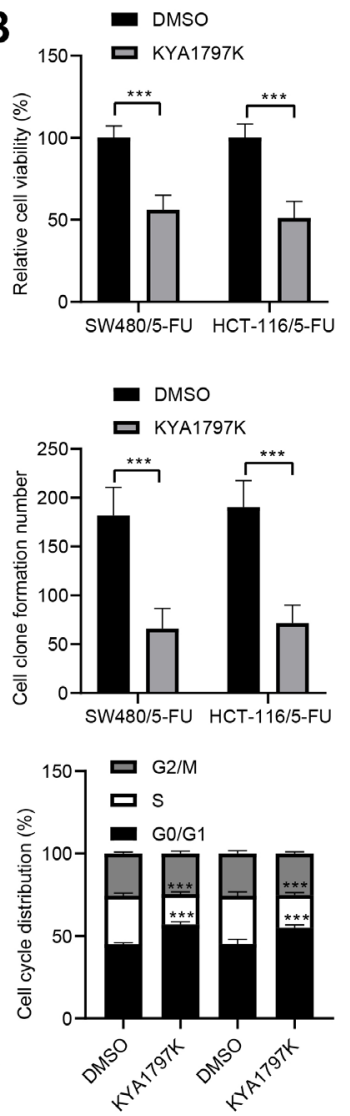

Figure 4. Downregulation of the Wnt/ $\beta$-catenin axis limits the resistance to 5 -FU in CRC. A) $\beta$-catenin level in SW480/5-FU and HCT-116/5-FU cells verified by western blot analysis. B) Cell viability assessed by MTT assay. C) Cell proliferation measured by the colony-formation assay. D) Cell cycle verified by a flow cytometer. Replicates $=3$. The data are shown as mean \pm standard deviation. The $t$-test and two-way ANOVA were used to analyze data. Tukey's multiple comparisons test was applied for the post hoc test. ${ }^{* *} \mathrm{p}<0.01,{ }^{* *} \mathrm{p}<0.001$ 
resistance to 5-FU in vivo, xenograft tumor model was established in nude mice as HCT-116 cells were stably transfected with sh-NC and sh-PITX2 in vivo and then treated with 5 -FU. The results revealed that sh-PITX $2+5-\mathrm{FU}$ could better inhibit tumor growth than sh-PITX2 or 5 -FU alone $(\mathrm{p}<0.05$, Figures 6A-6C). Afterward, levels of PITX2 and proteins related to the $\mathrm{Wnt} / \beta$-catenin axis (Wnt-3a and $\beta$-catenin) were examined, and the results unveiled that when PITX2 was silenced, protein levels of PITX2, Wnt-3a, and $\beta$-catenin were all restricted $(\mathrm{p}<0.05$, Figure $6 \mathrm{D})$. To further assess the efficiency of 5-FU, xenografts tumor tissue proliferation (Ki67) was quantified via immunohistochemical staining (Figure 6E), which showed that sh-PITX2+5-FU could better suppress CRC proliferation than sh-PITX2 or 5-FU alone $(\mathrm{p}<0.05)$. In that sense, the knockdown of PITX2 in vivo could attenuate HCT-116 cell resistance to 5-FU.
A

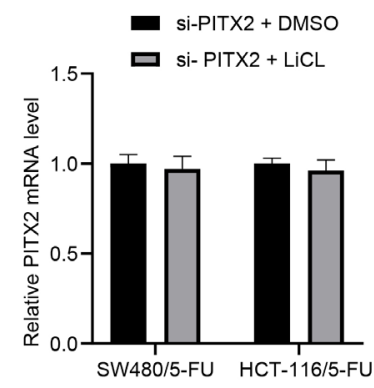

C

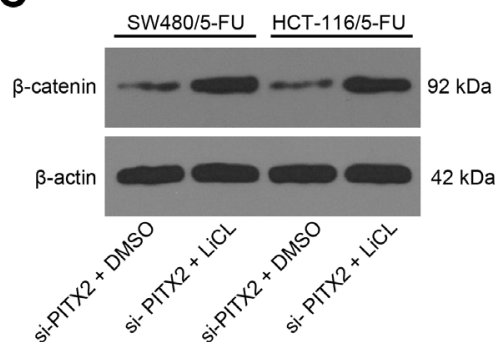

E
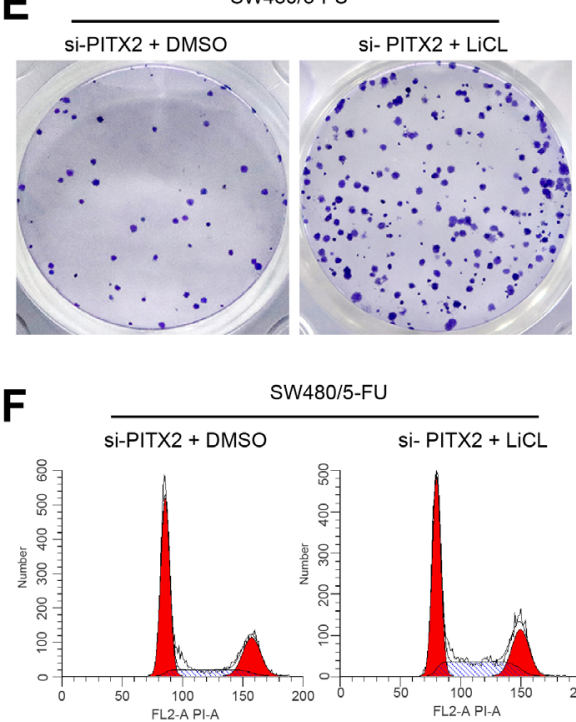

B

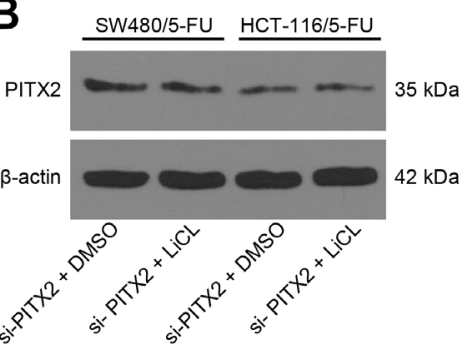

si-PITX2 + DMSO

口 si- PITX2 + LiCL
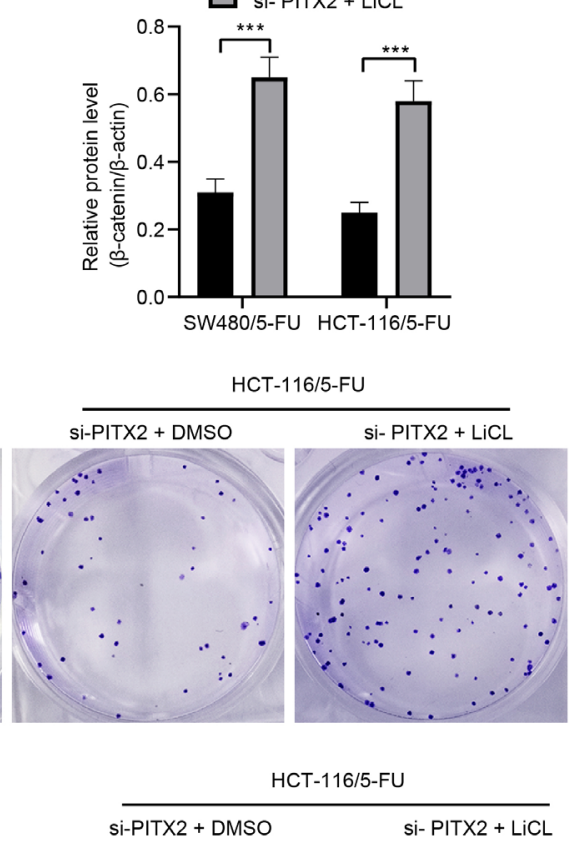
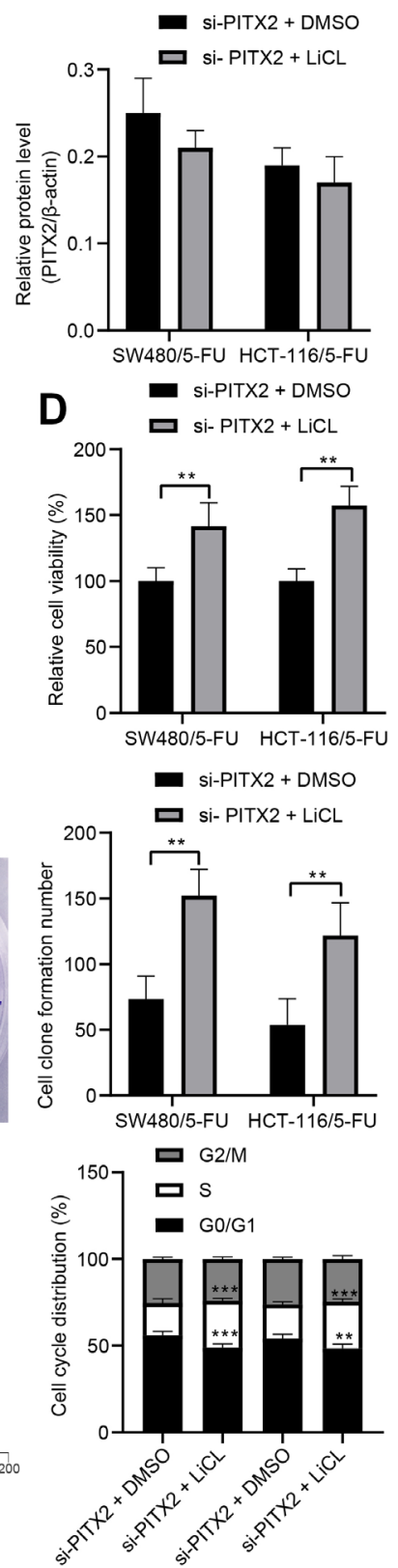

Figure 5. Activation of the Wnt/ $\beta$-catenin axis reverses the reduced resistance to 5-FU in CRC caused by PITX2 knockdown. Cells were subjected to pre-treatment of $20 \mathrm{mmol} / \mathrm{L} \mathrm{LiCl}$ for $24 \mathrm{~h}$ and then a transfection with si-PITX2. A) PITX2 expression verified qRT-PCR. B, C) PITX2 (B) and $\beta$-catenin (C) expression detected by western blot analysis. D) Cell viability assessed by MTT assay. E) Cell proliferation measured by the colony formation assay. F) Cell cycle verified by a flow cytometer. Replicates $=3$. The data are shown as mean \pm standard deviation. The t-test and two-way ANOVA were used to analyze data. Tukey's multiple comparisons test was applied for the post hoc test. ${ }^{* *} \mathbf{p}<0.01,{ }^{* * *} \mathrm{p}<0.001$ 

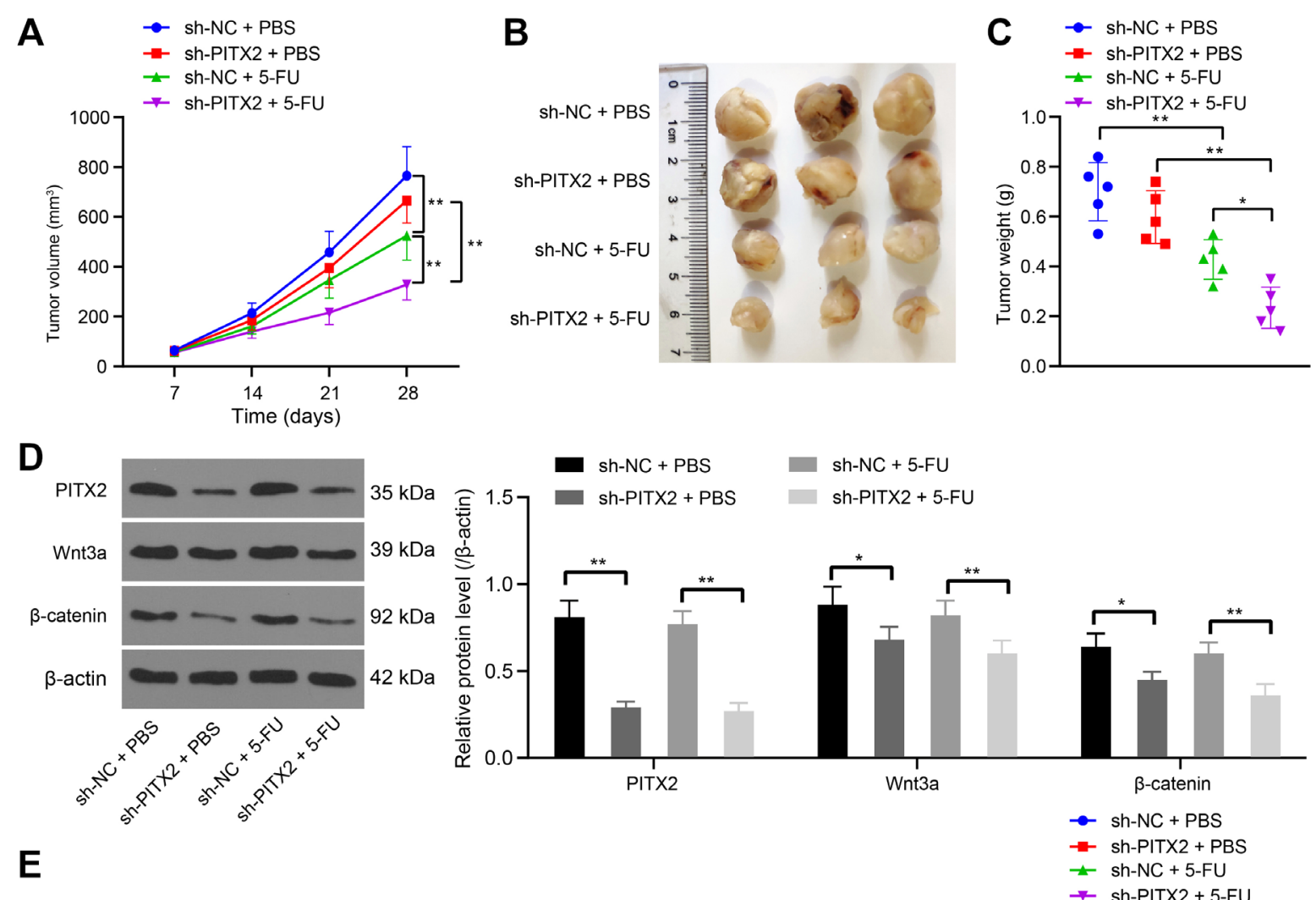

$\mathrm{E}$
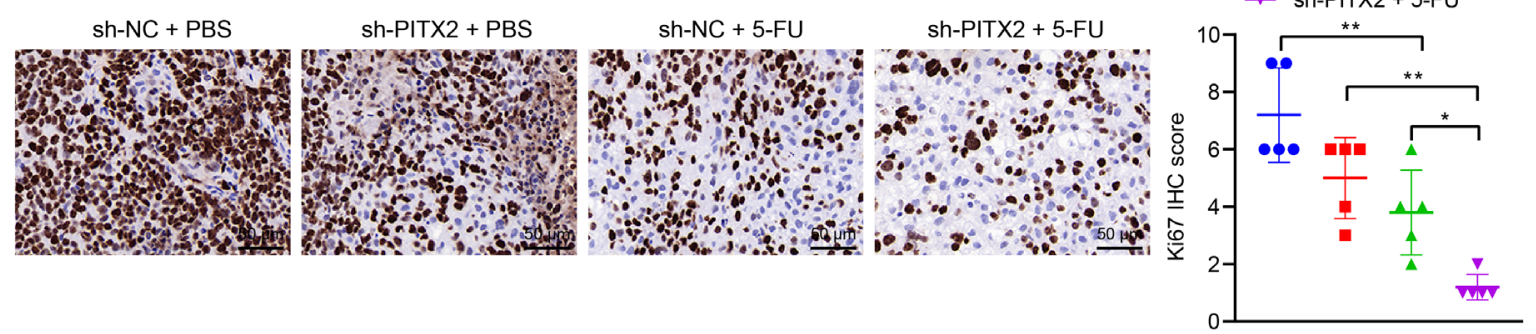

Figure 6. PITX2 knockdown in vivo attenuates HCT-116 cell resistance to 5-FU. A-C) Tumor volume (A), representative images of tumors (B), and analysis of tumor weights (C) of nude mice in each group. D) PITX2, Wnt 3a, and $\beta$-catenin expression determined by western blot analysis. E) Ki67 immunohistochemical staining. The data are shown as mean \pm standard deviation. One-way and two-way ANOVA were used to analyze data. Tukey's multiple comparisons test was applied for the post hoc test. ${ }^{\star} \mathrm{p}<0.05,{ }^{\star *} \mathrm{p}<0.01 ; \mathrm{n}=5$

\section{Discussion}

CRC represents a prevailing human cancer with a considerable body of patients diagnosed each year, and the malignancy of CRC and poor clinical outcome are directly related to chemoresistance $[20,21]$. PITX2 served as a conspicuous biomarker in cancer prognosis [22]. Besides, strongly expressed PITX2 was positively correlated with active cancer cellular activities and dangerous clinical outcomes [23]. In spite of the substantial quantity of literature on the relation of PITX2 and CRC, little was focused on the concrete crosstalk between PITX2 and drug resistance to CRC, which raised the difficulties of CRC remission. During the current experiment, we postulated that PITX2 knockdown might reduce chemoresistance in CRC via the manipulation of the related axis. Consequently, this report exhibited that the downregulation of PITX2 attenuated CRC by inactivating the Wnt/ $\beta$ catenin axis.

Initially, this research noticed that when CRC cells were consistently exposed to chemotherapy, they could develop a high level of chemoresistance. Chemotherapies were efficient in prolonged welfare and relief for cancer patients; while on the other hand, they may develop chemoresistance, which disrupted the treatment and led to carcinoma recurrence [24]. Moreover, the chemoresistance aggrandized by the unleashed release of tumor-associated macrophages in CRC brought about limited apoptosis induced by chemo medicine [25]. The first major result was that the knockout of PITX2 resulted in a reduction of chemoresistance in CRC. It was recently reported that PITX2 viability was markedly multi- 
plied in drug-resistant CRC, which confirmed the detrimental role of PITX2 in CRC and kidney cancer [10]. Convincingly, previous findings discussed that PITX2, the time-dependent cytokine in CRC, could function as a modulator in cancer cell biological behaviors to augment cellular growth, tumor malignancy, and disappointing prognosis [26]. What's more, PITX2 could activate Wnt-3a and thus upregulate the $W n t / \beta$-catenin axis. The Wnt axis belongs to the oncogenic or tumor-suppressive pathways, which contain a series of signaling responses and participated cellular activities and cancer progression via modulating tumor metastasis and epithelial-mesenchymal transition [27]. The interaction between PITX2 and the Wnt/ $\beta$-catenin axis is necessarily involved in a great number of human diseases, ranging from craniofacial dysmorphism, cardiac problems, glaucoma, and corneal dermoid [28]. On the other hand, PITX2 significantly improves cell biological behaviors and metastasis via the involvement with the $\mathrm{Wnt} / \beta$-catenin axis in different human cancers, such as ovarian cancer and breast cancer [29, 30 ], consolidating the accuracy and reliability of this experiment and our confidence to validate the relationship between PITX2 and the Wnt/ $\beta$-catenin axis in CRC.

Furthermore, our data supported that the downregulation of the Wnt/ $\beta$-catenin axis could restrict chemoresistance in CRC. Dysregulated Wnt signaling was one of the most major parts of tumor pathogenesis and growth, in particular in CRC $[12,31]$. The Wnt/ $\beta$-catenin axis referred to a family of proteins, and it served as a vital player in cell functional activities, including organogenesis and regeneration of stem cells [32]. Collectively, the activation of the Wnt/ $\beta$-catenin axis contributed to CRC exacerbation and made this malignancy more resistant to chemoradiotherapy [33]. In addition, the activation of the $\mathrm{Wnt} / \beta$-catenin axis reversed the reduced chemoresistance in CRC caused by PITX2 knockdown. In non-small-cell lung cancer, the upregulation of the Wnt/ $\beta$ catenin axis was found to be able to potentiate the decreased cancer cell metastasis and chemoresistance caused by the inhibition of oncogene [34]. Similarly, some oncogenes could augment CRC malignancy and chemoresistance via activating the Wnt/ $\beta$-catenin axis [35]. That's to say, the synchronous depletion of PITX 2 and the Wnt/ $\beta$-catenin axis could greatly quench the chemoresistance in CRC.

All in all, our study supported that the suppression of PITX2 could suppress chemoresistance in CRC by downregulating the Wnt/ $\beta$-catenin pathway via the in vivo and in vitro experiments. These results are promising in the prospect of promoting the future treatment of $\mathrm{CRC}$, thereby providing references for optimizing individual treatment for CRC patients. Though our findings offer therapeutic implications in CRC treatment, the experimental results and effective application into clinic practice still need in-depth validation. However, due to the limitation of experimental funding, the number of nude mice in each group might be insufficient; which might lead to the deviation in our results; besides, this study only applied HCT-116 cells for in vivo verifica- tion. Thus, in future research, we plan to seek the upstream mechanism of PITX2 in CRC cell resistance to 5-FU.

Acknowledgments: This study was supported by the National Natural Science Foundation of China (No. 81760442).

\section{References}

[1] LECH G, SLOTWINSKI R, SLODKOWSKI M, KRASNODEBSKI IW. Colorectal cancer tumour markers and biomarkers: Recent therapeutic advances. World J Gastroenterol 2016; 22: 1745-1755. https://doi.org/10.3748/wjg.v22. i5.1745

[2] BRENNER H, KLOOR M, POX CP. Colorectal cancer. Lancet 2014; 383: 1490-1502. https://doi.org/10.1016/S01406736(13)61649-9

[3] GAO R, GAO Z, HUANG L, QIN H. Gut microbiota and colorectal cancer. Eur J Clin Microbiol Infect Dis 2017; 36: 757-769. https://doi.org/10.1007/s10096-016-2881-8

[4] DEKKER E, TANIS PJ, VLEUGELS JLA, KASI PM, WALLACE MB. Colorectal cancer. Lancet 2019; 394: 1467-1480. https://doi.org/10.1016/S0140-6736(19)32319-0

[5] THANIKACHALAM K, KHAN G. Colorectal Cancer and Nutrition. Nutrients 2019; 11: 164. https://doi.org/10.3390/ nu11010164

[6] WEI L, WANG X, LV L, ZHENG Y, ZHANG N et al. The emerging role of noncoding RNAs in colorectal cancer chemoresistance. Cell Oncol (Dordr) 2019; 42: 757-768. https:// doi.org/10.1007/s13402-019-00466-8

[7] AUBELE M, SCHMITT M, NAPIERALSKI R, PAEPKE S, ETTL J et al. The Predictive Value of PITX2 DNA Methylation for High-Risk Breast Cancer Therapy: Current Guidelines, Medical Needs, and Challenges. Dis Markers 2017; 2017: 4934608. https://doi.org/10.1155/2017/4934608

[8] PELLATT AJ, MULLANY LE, HERRICK JS, SAKODA LC, WOLFF RK et al. The TGFbeta-signaling pathway and colorectal cancer: associations between dysregulated genes and miRNAs. J Transl Med 2018; 16: 191. J Transl Med 2018; 16: 191. https://doi.org/10.1186/s12967-018-1566-8

[9] SEMAAN A, UHL B, BRANCHI V, LINGOHR P, BOOTZ F et al. Significance of PITX2 Promoter Methylation in Colorectal Carcinoma Prognosis. Clin Colorectal Cancer 2018; 17: e385-e393. https://doi.org/10.1016/j.clcc.2018.02.008

[10] LEE WK, THEVENOD F. Oncogenic PITX2 facilitates tumor cell drug resistance by inverse regulation of hOCT3/ SLC22A3 and ABC drug transporters in colon and kidney cancers. Cancer Lett 2019; 449: 237-251. https://doi. org/10.1016/j.canlet.2019.01.044

[11] BANACZEK Z, PENZA G. [Evaluation of a seven year period of managing pregnancies complicated by diabetes mellitus]. Ginekol Pol 1995; 66: 76-79.

[12] GAN T, STEVENS AT, XIONG X, WEN YA, FARMER TN et al. Inhibition of protein tyrosine phosphatase receptor type F suppresses Wnt signaling in colorectal cancer. Oncogene 2020; 39: 6789-6801. https://doi.org/10.1038/s41388020-01472-z 
[13] GAO J, YU SR, YUAN Y, ZHANG LL, LU JW et al. MicroRNA-590-5p functions as a tumor suppressor in breast cancer conferring inhibitory effects on cell migration, invasion, and epithelial-mesenchymal transition by downregulating the Wnt-beta-catenin signaling pathway. J Cell Physiol 2019; 234: 1827-1841. https://doi.org/10.1002/jcp.27056

[14] LUO J, YAO Y, JI S, SUN Q, XU Y et al. PITX2 enhances progression of lung adenocarcinoma by transcriptionally regulating WNT3A and activating Wnt/beta-catenin signaling pathway. Cancer Cell Int 2019; 19: 96. https://doi. org/10.1186/s12935-019-0800-7

[15] LIU Y, HUANG Y, ZHU GZ. Cyclin A1 is a transcriptional target of PITX2 and overexpressed in papillary thyroid carcinoma. Mol Cell Biochem 2013; 384: 221-227. https://doi. org/10.1007/s11010-013-1801-9

[16] HE P, XIONG G, GUO W, JIANG G, LI Y et al. Long noncoding RNA CCAT2 promotes prostate cancer cell proliferation and invasion by regulating the Wnt/beta-catenin signaling pathway. Oncol Lett 2020; 20: 97. https://doi.org/10.3892/ ol.2020.11958

[17] OU J, PENG Y, YANG W, ZHANG Y, HAO J et al. ABHD5 blunts the sensitivity of colorectal cancer to fluorouracil via promoting autophagic uracil yield. Nat Commun 2019; 10: 1078. https://doi.org/10.1038/s41467-019-08902-x

[18] SONG R, GU D, ZHANG L, ZHANG X, YU B et al. Functional significance of Hippo/YAP signaling for drug resistance in colorectal cancer. Mol Carcinog 2018; 57: 16081615. https://doi.org/10.1002/mc.22883

[19] LIU H, WU Z, ZHOU H, CAI W, LI X et al. The SOX4/ miR-17-92/RB1 Axis Promotes Prostate Cancer Progression. Neoplasia 2019; 21: 765-776. https://doi.org/10.1016/j. neo.2019.05.007

[20] YIU AJ, YIU CY. Biomarkers in Colorectal Cancer. Anticancer Res 2016; 36: 1093-1102.

[21] YU T, GUO F, YU Y, SUN T, MA D et al. Fusobacterium nucleatum Promotes Chemoresistance to Colorectal Cancer by Modulating Autophagy. Cell 2017; 170: 548-563.e16. https:// doi.org/10.1016/j.cell.2017.07.008

[22] EGEVAD L, DELAHUNT B, KRISTIANSEN G, SAMARATUNGA H, VARMA M. Contemporary prognostic indicators for prostate cancer incorporating International Society of Urological Pathology recommendations. Pathology 2018; 50: 60-73. https://doi.org/10.1016/j.pathol.2017.09.008

[23] HIROSE H, ISHII H, MIMORI K, TANAKA F, TAKEMASA I et al. The significance of PITX2 overexpression in human colorectal cancer. Ann Surg Oncol 2011; 18: 3005-3012. https://doi.org/10.1245/s10434-011-1653-z

[24] BEGICEVIC RR, FALASCA M. ABC Transporters in Cancer Stem Cells: Beyond Chemoresistance. Int J Mol Sci 2017; 18: 2362. https://doi.org/10.3390/ijms18112362
[25] YIN Y, YAO S, HU Y, FENG Y, LI M et al. The Immunemicroenvironment Confers Chemoresistance of Colorectal Cancer through Macrophage-Derived IL6. Clin Cancer Res 2017; 23: 7375-7387. https://doi.org/10.1158/1078-0432. CCR-17-1283

[26] CHEN G, HAN N, LI G, LI X, LI G et al. Time course analysis based on gene expression profile and identification of target molecules for colorectal cancer. Cancer Cell Int 2016; 16: 22. https://doi.org/10.1186/s12935-016-0296-3

[27] VELA I, MORRISSEY C, ZHANG X, CHEN S, COREY E et al. PITX2 and non-canonical Wnt pathway interaction in metastatic prostate cancer. Clin Exp Metastasis 2014; 31: 199-211. https://doi.org/10.1007/s10585-013-9620-7

[28] HENDEE KE, SOROKINA EA, MUHEISEN SS, REIS LM, TYLER RC et al. PITX2 deficiency and associated human disease: insights from the zebrafish model. Hum Mol Genet 2018; 27: 1675-1695. https://doi.org/10.1093/hmg/ddy074

[29] FUNG FK, CHAN DW, LIU VW, LEUNG TH, CHEUNG AN et al. Increased expression of PITX2 transcription factor contributes to ovarian cancer progression. PLoS One 2012; 7 : e37076. https://doi.org/10.1371/journal.pone.0037076

[30] PILLAI SG, DASGUPTA N, SIDDAPPA CM, WATSON MA, FLEMING T et al. Paired-like Homeodomain Transcription factor 2 expression by breast cancer bone marrow disseminated tumor cells is associated with early recurrent disease development. Breast Cancer Res Treat 2015; 153: 507-517. https://doi.org/10.1007/s10549-015-3576-Z

[31] ZHAN T, RINDTORFF N, BOUTROS M. Wnt signaling in cancer. Oncogene 2017; 36: 1461-1473. https://doi. org/10.1038/onc.2016.304

[32] KRISHNAMURTHY N, KURZROCK R. Targeting the Wnt/beta-catenin pathway in cancer: Update on effectors and inhibitors. Cancer Treat Rev 2018; 62: 50-60. https://doi. org/10.1016/j.ctrv.2017.11.002

[33] EMONS G, SPITZNER M, REINEKE S, MOLLER J, AUSLANDER $\mathrm{N}$ et al. Chemoradiotherapy Resistance in Colorectal Cancer Cells is Mediated by Wnt/beta-catenin Signaling. Mol Cancer Res 2017; 15: 1481-1490. https://doi. org/10.1158/1541-7786.MCR-17-0205

[34] CAI J, FANG L, HUANG Y, LI R, XU X et al. Simultaneous overactivation of Wnt/beta-catenin and TGFbeta signalling by miR-128-3p confers chemoresistance-associated metastasis in NSCLC. Nat Commun 2017; 8: 15870. https://doi. org/10.1038/ncomms 15870

[35] HAN P, LI JW, ZHANG BM, LV JC, LI YM et al. The lncRNA CRNDE promotes colorectal cancer cell proliferation and chemoresistance via miR-181a-5p-mediated regulation of Wnt/beta-catenin signaling. Mol Cancer 2017; 16: 9. https://doi.org/10.1186/s12943-017-0583-1 